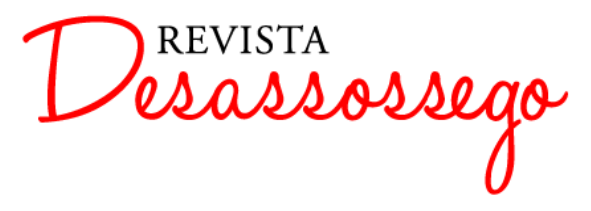

DESASSOSSEGO $17 \quad$ JUN/2017 | ISSN 2175-3180

DOI: http://dx.doi.org/10.11606/issn.2175-3180.v9i17p214-217

\title{
PASSAGENS: UMA MEDITAÇÃO
}

Bruno Mazolini de Barros ${ }^{1}$

Teolinda Gersão é uma das mais celebradas e competentes escritoras portuguesas e, em mais de três décadas de produção artística, conta com publicações de crônicas, contos e romances. Estudou Germanística, Romanística e Anglística nas Universidades de Coimbra, Tübingen e Berlim, e foi professora catedrática da Universidade Nova de Lisboa, onde lecionou até 1995. A autora, ainda com poucas publicações no Brasil, recebeu diversos prêmios significativos em Portugal, como o Pen Club e o Prémio Literário Fernando Namora, e possui obras traduzidas para diversas línguas europeias e para o árabe.

As epígrafes deste seu último romance - uma citação Michel de Montaigne e outra de Walter Benjamin -, juntamente com o título, Passagens, já anunciam o tema sobre o qual ele está erigido: a transição de tudo, e, consequentemente, o seu fim. É um texto sobre a morte, mas também sobre a vida de Ana, a protagonista da narrativa e do velório apresentado nas primeiras páginas: "Estava deitada, era a única pessoa deitada, mas tinha uma visão perfeita do que se passava em volta. Do mesmo modo que ouvia perfeitamente, mesmo quando falavam muito baixo, quase em segredo" (GERSÃO, 2014, p. 11).

O texto está organizado como uma peça em três atos, e o narrador em terceira pessoa mostra-se diretamente somente no início da primeira parte e, na segunda parte, em pequenas intervenções, simples como pequenas rubricas. A primeira parte é intitulada "Ponto de encontro", que é o velório, o momento no qual a família da Ana reúne-se para o primeiro momento de despedida da matriarca: Marta, a filha; Rosinha, a sobrinha que foi morar com Ana na infância; Madalena, filha de Rosinha, e seu marido, Miguel; António, marido de Marta, e Fernando, ex-marido; Hugo, neto de Ana, filho de Marta; Eduardo, marido de Madalena; Luísa, a nova mulher de António; além de outros parentes e Conceição, uma cuidadora do asilo onde Ana residiu.

Depois que o narrador apresenta um plano geral do caixão rodeado de pessoas, a narrativa passa a ser composta pelo fluxo de consciência de cada uma das personagens, que são “ouvidas" por Ana. As relações de todas elas, sejam com Ana ou entre si, são recuperadas no texto gradativamente, à medida que as memórias e projeções de cada um dos familiares são expostas ao leitor. Essas histórias pessoais e familiares - casamentos

\footnotetext{
${ }^{1}$ Mestre e doutorando em Teoria da Literatura - Pontifícia Universidade Católica do Rio Grande do Sul PUCRS.
} 


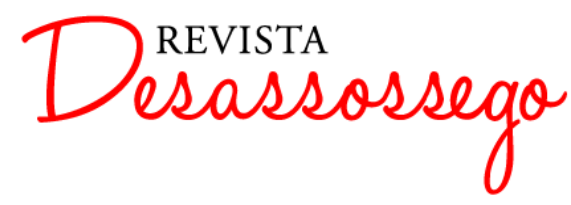

desfeitos, ressentimentos, mentiras, amores e saudades - estão organizadas em blocos descontínuos de texto, intitulados com os nomes das respectivas personagens. Nessa primeira parte, as personagens relembram também experiências que tiveram ao visitarem Ana na casa de repouso, além de sua condição de saúde no final da vida e, assim, tem-se acesso até ao processo de luto de algumas delas.

Na segunda parte do romance, "Noite", em um desdobramento de si mesma, Ana e seu duplo mantêm um diálogo inquisitivo, no qual estão em jogo a sua história pessoal e as diferentes decisões que acabaram guiando a sua vida para o percurso que teve. Nessa conversa entre Ana 1 e Ana 2, toma-se conhecimento de um passado mais longínquo da falecida, e da história de seus pais, das diferentes máscaras que cada um dos parentes assumiram e das consequências dessas vidas inventadas e encenadas. Com o passado revisitado, emerge uma face pouco conhecida da família e dúvidas acerca da morte do pai de Ana.

Agora morta, ela pode contar para si mesma, e para seu duplo, a verdadeira história de seu progenitor, que gastou todas as economias da família, viajou para o Brasil e voltou somente porque precisava de ajuda. Em uma conversa na qual uma Ana retifica ou questiona a outra, um cenário obscuro das relações familiares é apresentado: histórias que têm uma parte oculta para cada um dos parentes e que foram recontadas entre eles, em diferentes versões. Mesmo o final da vida de Ana tem um aspecto desconhecido pelos seus familiares: ela, em um primeiro momento, está fingindo para a família que está com Alzheimer; no entanto, falece por complicações médicas relacionadas a esta doença que, efetivamente, acaba desenvolvendo.

Ana 1 e Ana 2 concluem, no final da segunda parte, sem julgamentos pejorativos mas em regozijo, que a vida é uma encenação:

Ana 1

Estou cercada de flores, de gratidão, de aplausos. De amor. É assim que irei desaparecer.

Ana 2

Quando a peça acabar e cair o pano.

Ana 1

Sim, a peça está quase a terminar. Já não iremos dizer mais nada, são agora os outros que vão entrar no palco: dirão as suas falas pegando nas deixas uns dos outros, farão os gestos e os movimentos certos, cumprirão todas as marcações (GERSÃO, 2014, p. 130).

Essa ideia, que está tanto na estrutura em três atos quanto no próprio discurso da 


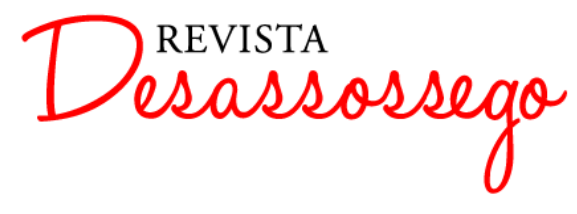

personagem, já aparece no início do romance também: "São puro teatro, as nossas relações. Fica bem não ter ressentimentos, haver um convívio pacífico entre as famílias que se desintegram e as que se formam, a partir delas" (GERSÃO, 2014, p. 29). Principalmente nas duas primeiras partes de Passagens, os papéis na encenação da vida são revistados, e até relações novas são estabelecidas pelo elenco do velório.

A terceira parte, "A cerimônia", em um jogo metaficcional, funciona como indicado por Ana 1 e Ana 2 no final da segunda. O início do último segmento do romance anuncia o tom geral da narrativa que, apesar de ser sobre a morte, tem esse aspecto solar, e não sombrio: "Tudo acontece agora sob o signo do fogo: da transformação e da luz" (GERSÃO, 2014, p. 133): Isso se passa na mente de Joana, porém, mais ainda do que na primeira parte, apesar de o texto estar fragmentado em diversos blocos demarcados com os nomes das personagens, a narrativa flui, a partir deste ponto, em um só rumo, homogêneo: como em uma contemplação una.

Encadeadamente, os familiares vão analisando, questionando e contemplando o sentido da vida e o da morte. O ambiente da despedida é leve: "Cada um recolhendo-se dentro de si, em silêncio. E flores como um sinal de afecto e uma forma alegre de a deixar partir" (GERSÃO, 2014, p. 139). Eles meditam como a morte acomete ao corpo, detalhadamente, como o processo da parada do funcionamento dos órgãos acontece, passando pelo modo como ocorre uma cremação e até sobre o que resta após ela. Tudo isso vem acompanhado de meditações sobre a limitação do conhecimento e da condição humana, sobre a maternidade, sobre o nascimento e, recorrentemente, sobre a morte.

Dessa maneira, em Passagens, Teolinda Gersão não apresenta somente uma recapitulação dos momentos críticos da vida e da morte de Ana, mas dramatiza também, especialmente, o final da vida, e os conflitos que podem envolver a velhice. No texto, os desafios apresentados são tanto para os que envelhecem quanto para os que acompanham o processo: Ana quer ter controle de tudo, e prefere viver em uma casa de repouso do que na casa da filha (por isso fingiu Alzheimer), mas as limitações físicas impõem-se contra ela; a filha Marta tem ressalvas sobre cuidar da mãe em casa, mas tem receios sobre os cuidados que a mãe pode vir a receber no lar de idosos. Ao mesmo tempo, aparecem no romance situações periféricas, mas significativas, que envolvem a velhice: a dificuldade com e dos cuidadores, as complicações na saúde (locomoção comprometida, acidentes vasculares, etc.), e questões como o abandono de idosos e o comércio que envolve as casas de repouso. 


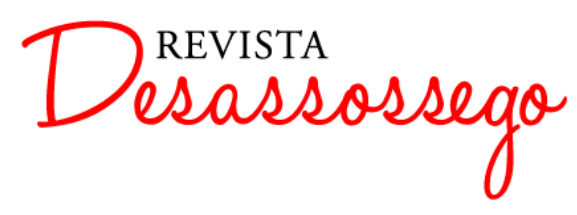

DESASSOSSEGO $17 \quad$ JUN/2017 | ISSN 2175-3180

DOI: http://dx.doi.org/10.11606/issn.2175-3180.v9i17p214-217

Em meio a tudo isso, ao fluxo de consciência dos parentes e às histórias de vida de Ana, vale destacar a vOz dissonante das cuidadoras de pacientes geriátricos, principalmente a voz de Conceição. Entre a primeira aparição de Marta e a dos outros membros da família, aparecem, em um interlúdio, as reclamações e críticas das funcionárias da casa de repouso. É significativa, no entanto, a presença de Conceição, a cuidadora solicitada pela chefe a participar do velório. Da mesma forma que se passa a saber da vida dos familiares de Ana, a vida de uma classe média bem estabelecida, tem-se acesso também às experiências e algumas histórias de Conceição, moradora do subúrbio.

No entanto, a importância de sua presença no romance não é só pelo fato de ela ser alguém de classe social e de educação diversas dos que estão no velório, é também por Conceição, diferentemente das outras personagens na primeira parte, apresentar um outro lado do processo de envelhecimento. Tensa no velório, em uma conversa mental com a defunta, ela aborda o aspecto prático, e algumas vezes sofridos, da velhice, tanto de quem passa quanto de quem lida com ela. É uma experiência que nenhum dos parentes de Ana compartilham:

Pois como eu lhe estava a dizer, dona Ana, é mesmo um dos piores trabalhos, mijo, merda e vomitado e fraldas sujas, e a gente a pegar nas senhoras em peso e faltarem-nos as forças, por causa disso arranjei uma hérnia e já fui operada à coluna duas vezes, mas mesmo assim tenho muitas dores. E não fui só eu a ser operada, também a Irene e a Fátima e a Lurdes e a Fortunata e a Jacinta (GERSÃO, 2014, p. 37).

Em pouco tempo, entre o velório e a cremação, tem-se toda vida e morte de Ana, a matriarca da família, que funciona como eixo da existência de cada uma das personagens no romance. Em meio aos impasses, conflitos e desafios emocionais e práticos de Ana e de seus familiares, o livro traz diversas reflexões, semelhantes às de Montaigne e Benjamin na abertura de Passagens: "É apenas uma viagem. Também nós, os vivos, andamos em viagem, a cada instante mudamos de visão e perspectiva, o nosso mundo interior é um contínuo, tudo é sempre uma sucessão de passagens" (GERSÃO, 2014, p. 141). Dessa maneira, Teolinda Gersão dá ao seu romance, pelo tratamento do tema e pela forma de estruturá-lo, um tom de uma grande meditação sobre passagens: de relações, de verdades, de vidas, de mortes.

\section{Referências}

GERSÃO, Teolinda. Passagens. Porto: Porto Editora, 2014. 